of its polypeptide chain is located on the outer surface of the membrane [K. C. Chaudhary, M. S. Nijjar., 1988] affects the function of cilia of ciliary cells of the epithelium. The obtained data on the localization and activity of the AC allow us to conclude that in intact rats in the mucosa the greatest activity of the adenylate cyclase is found on the surface of the cilia of the single-layered multi-row ciliated epithelium and on the surface of the endothelium of the blood capillaries of the submucosa of the trachea. As for the activity of adenylate cyclase in the experiment, with prolonged cold exposure, the intensity of its work in the ciliated epithelium of the mucosa decreases. Conversely, there is an increase in the activity of the active center on the surface of the endothelium and erythrocytes in the submucous capillary capillaries. Assessing the function of the ciliated epithelium, especially in the situation with cold exposure, it is necessary to pay attention to the concentration of cyclic nucleotides, which determine pathological changes in the mucociliary conveyor.

\title{
References:
}

1. Philip W. Shaul, Kathryn H. Muntz, Donald DeBeltz, and L. Maximilian Buja //Effects of Prolonged Hypoxia on Adenylate Cyclase Activity and /-Adrenergic Receptors in Pulmonary and Systemic Arteries of the Rat, J. Circulation Research Vol. 66, No 6, June 1990. S.1526-1534. (http://circres.ahajournals.org/content/circresaha/66/6/1526.full.pdf).

2. Chaudhary K. C., Nijjar M. S.. //Endocrine Control of Cytosolic Factors Stimulating Adenylate Cyclase in Rat Lung ,Horm. Metab. Res. 1988; 20(10): 624-629, DOI: 10.1055/s-2007-1010901. (https://www.thieme-connect.com/products/iournals/abstract/10.1055/s-2007-1010901).

UDC 663 DOI 10.22448/AMJ.2017.3.77-79

\section{THE STUDY OF THE DYNAMICS OF ACIDITY DURING THE FERMENTATION OF THE COMPOSITE MIXTURE}

\author{
Utochkina E.A., Kupriyanova G.A.
}

\author{
Amur State Medical Academy, Blagoveshchensk, Amur Region, Russia
}

\begin{abstract}
The article presents the results of studying the effect of arabinogalactan extracted from larch Daurskaya on the formation of the properties of the fermented milk product. The optimal dose of introducing arabinogalactan into the composite mixture was determined.
\end{abstract}

Key words: functional food products, probiotic, prebiotic, arabinogalactan, fermented product.

When producing dihydroquercetin from larch, a significant amount of biologically active substances can be obtained as a byproduct. One such biologically active substance is arabinogalactan.

From the middle of the last century domestic and foreign scientists have been studying its structure and properties. Arabinogalactan is found in immunomodulating herbs (Echinacea purpurea, Baptisia tinctoria, Angelica Acutiloba, and Curcuma longa), but the study of the arabinogalactan extracted from larch is of the greatest interest, since it constitutes a significant part of its biomass. The heartwood of some species of larch comprises up to $35 \%$ of arabinogalactan [1].

In recent years, the study of the biological activity of arabinogalactan has been intensified. The difference of arabinogalactan from many polysaccharides has been reported in terms of physico-chemical properties such as low viscosity of concentrated aqueous solutions, high solubility in water, resistance to acid environment, thermal and hydrolytic stability, and good dispersing ability [2]. It was found that arabinogalactan has a significant membranotropic and antimicrobial action against certain bacteria as well as immunomodulating property $[3,4]$ and antimutagenic activity [4].

The prebiotic ability is of particular interest in studying the properties of arabinogalactan. The results of studies of foreign and domestic scientists show the effect of larch arabinogalactan as a nutrient medium for Lactobacilli and Bifidobacteria since it is a fermentable fiber.

Arabinogalactan serves as food to beneficial symbiotic bacteria in the colon. In turn it helps to reduce the growth of pathogenic bacteria $[1,5,7,6]$.

Over the past few years because of its multifunction properties arabinogalactan has been aggressively introduced in the production of dietary supplements and foods. Thanks to the dispersing ability it is relevant to use arabinogalactan in the development of formulas of yogurt, juices, pastries, confectionery, powdered milk, and other foods rich in mineral supplements and vitamin complexes.

Arabinogalactan mixes well with all kinds of food and does not affect the organoleptic properties of the finished product. It is a source of dietary fiber and has a positive impact on the gastrointestinal tract. It can be recommended as a nutraceutical or functional food supplement in the human diet [8].

Based on the above, studies were carried out in order to assess the possibility of using arabinogalactan extracted from the larch as a functional ingredient adding probiotic and prebiotic properties, improving traditional technologies, intensifying the process of fermentation of soy milk mixture, improving physical, chemical, and organoleptic properties, and microbiological parameters of the fermented milk product.

In the course of work the effect of the portion of arabinogalactan extracted from the larch on the formation of qualitative properties of the fermented milk product was investigated, in particular on the dynamics of titratable acidity. 
Arabinogalactan is the main part of intracellular wood polysaccharides that performs protective functions and contains bioactive nutrients.

In terms of organoleptic parameters arabinogalactan is an amorphous pale cream dry powder with a light almost impalpable pine smell and faint sweet flavor.

In the experiment, five samples of the composite mixture (skimmed milk and soy-based food in the ratio of 70:30) enriched with arabinogalactan in an amount of 0.5 to $2.5 \%$ were used. The sample of the mixture without arabinogalactan served as the control.

The mixture was fermented with the starter culture composition YF-L811 (Streptococcus thermohilus, Lactobacillus delbrueckii subsp. bulgaricus) and BB-12 (Bifidobacterium lactis) in the ratio of 1:1.

During the fermentation the dynamics of the acid formation of clots depending on the portion of arabinogalactan was investigated. The fermentation was carried out at a temperature of $(40 \pm 2) \stackrel{\circ}{ } \mathrm{C}$ for 6 hours. The titratable acidity was determined at intervals of 1 hour. The results are presented in Fig. 1.

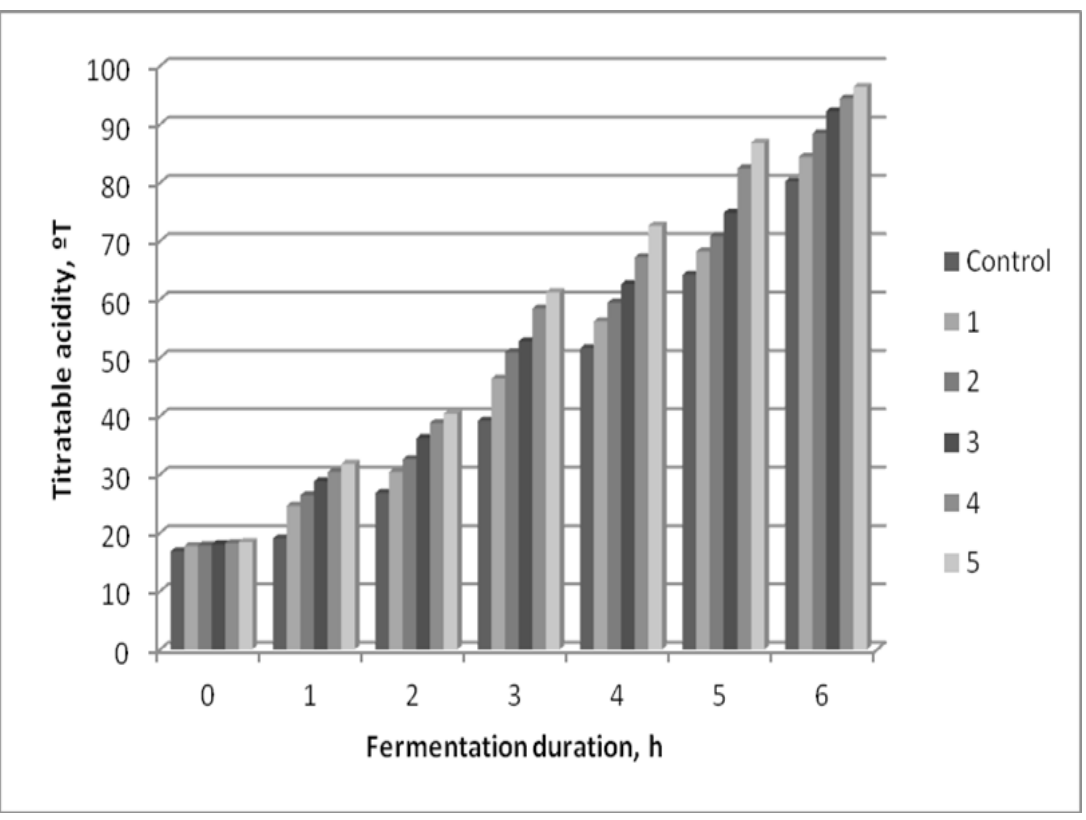

Fig. 1 The titratable acidity of the clot depending on the portion of arabinogalactan: control is without arabinogalac$\tan , 0.5 \%(1), 1.0 \%(2), 1.5 \%(3), 2.0 \%(4)$, and $2.5 \%(5)$.

The analysis of the obtained data suggests that as a result of introduction of arabinogalactan in the composite mixture the fermentation time is greatly reduced. It can be associated with an increase in dry matter content in the mixture and the stimulating effect of the introduced polysaccharide on the microflora of starter cultures. It was found that if the portion of arabinogalactan is $0.5,1.0,1.5,2.0$, and $2.5 \%$ the titratable acidity of samples increases intensively by $4.5 \%, 11.3 \%, 17.0 \%, 20.1 \%$, and $23.0 \%$, respectively, compared to the control sample.

The analysis of organoleptic characteristics of the analyzed samples indicates that the introduction of arabinogalactan has no effect on the taste and smell of the product. All the obtained clots had high quality organoleptic characteristics, i.e., they had taste and smell of sour milk, the soy component was almost not felt, the color was white with a cream tint, they were uniform throughout the mass.

The received results of researches, testify, that the use of arabinogalactan intensifies the fermentation of the composite mixture (skimmed milk and soy-based food in the ratio of 70:30) which accordingly reduces the production cycle of the product. The application rate of $1.5 \%$ arabinogalactan in the composite mixture has been found.

The expediency of the use of arabinogalactan in the production of dairy products is proved.

Summing up the above, we can conclude that the study of the enrichment of food with components with prebiotic properties is relevant in the field of technology of production of functional foods.

\section{References}

1. Reshetnik, E.I. and Utochkina, E.A., Prakticheskie aspekty proektirovaniya funktsional'nykh produktov pitaniya: monografiya (Practical Aspects of the Design of Functional Foods: Monograph), Blagoveshchensk: DalGAU, 2012.

2. Reshetnik, E.I., Utochkina, E.A., and Maksimyuk, V.A., Fermented milk product with arabinogalactan, Molochn. Prom-st., 2011, no. 11 , pp. 56-57.

3. Dubrovin, V.I., Medvedeva, S.A., Aleksandrova, G.P., et al., Immunomodulatory properties of arabinogalactan of Siberian larch (Larix sibirica L.), Farmatsiya, 2001, no. 5, pp. 26-27. 
4. Belicova, A., Ebringer, L., Krajcovic, J., Hromadkova, Z., and Ebringerova, A., Antimutagenic effect of heteroxilans, arabinogalactans. pectins and mannans in the euglena assay, World J. Microbiol. Biotechnol., 2001, vol. 17, no. 3, pp. $293-299$.

5. Grieshop, S.M., Flickinger, E.A., and Eahey, G.C., Oral administration of Arabinogalactan affects immune status and fecal microbial populations in dogs, J. Nutr., 2002, vol. 132, no. 3, pp. 478-482.

6. Robinson, R.R., Causey, J., and Slavin, J.L., Nutritional Benefits of Larch Arabinogalactan, McCleary, B.V. and Prosky, L., Eds., Oxford, UK: Blackvvell Science, 2001, pp. 443-451.

7. Robinson, R.R., Feirtag, J., and Slavin, J.L., Effects of dietary arabinogalactan on gastrointestinal and blood parameters in healthy human subjects, J. Am. Coll. Nutr., 2001, vol. 20, no. 4, pp. 279-285.

8. Medvedeva, E.N., Babkin, V.A., and Ostroukhova, V.A., Larch arabinogalactan--properties and prospects for the use (review), Khim. Rastit. Syr'ya, 2003, no. 1, pp. 27-37.

UDC 616.441-007.5-089 DOI 10.22448/AMJ.2017.3.79-80

\section{RESULTS OF SURGICAL TREATMENT OF NODULAR GOITER IN THE REGION OF ENDEMIC GOITER}

\section{N.P. Volodchenko, N.V. Valova, V.V. Ishchenko, Kravtsova S.V, Shevcheko E.A., Ishchenko T.K}

Amur State Medical Academy, CAPHD AR “Blagoveshchensk City Clinical Hospital”. Blagoveshchensk, Russia

Nodular goiter is the main pathology of the thyroid gland and ranges from $42 \%$ up to $98 \%$ in endemic regions of Russia $(2,3,4)$. The wide prevalence of nodular pathology of the thyroid gland sometimes causes considerable difficulties in choosing the optimal method of treatment and the volume of surgical intervention. Despite the large experience of surgical treatment of nodular goiter, the number of postoperative complications is $7-8 \%$, the frequency of postoperative relapse does not decrease and reaches $0,5 \%-12 \%(1,2,3,4)$.

The purpose of the research: to study the results of surgical treatment of patients with nodular thyroid formations.

Material and methods The results of operative treatment of 112 patients with nodular formations of the thyroid gland, operated in the city clinical hospital, are analyzed. There were 109 women $(97.3 \%)$ and $3(2.7 \%)$ men, aged 23 up to 76 years old. The diagnostic algorithm included: analysis of clinical symptoms, assessment of the history of the disease, clinical and biochemical blood tests, assessment of thyroid hormone function (study of TTG, T4 (free), T3 in blood serum), ultrasound and thyroid TAB. Indications for surgery were: large sizes of nodes, causing neck deformation and cervical compression syndrome, signs of malignant growth, retrosternal site of the nodes, relapse of the disease. All patients were operated under anesthesia. The amount of surgical intervention depended on the nature of the pathological process.

Distribution of patients depending on the volume of the operation

\begin{tabular}{|ll|}
\hline Type of operation & Number of transactions \\
\hline Hemithyroidectomy (GE) & $32(28,6 \%)$ \\
\hline Thyroidectomy(FC) & $41(36,6 \%)$ \\
\hline Subtotal resection (CP) & $39(34,8 \%)$ \\
\hline Total & $112(100 \%)$ \\
\hline
\end{tabular}

Results and discussion

Early postoperative complications were observed in 7 (6.3\%) patients, in 3 patients - unilateral and in 1 - bilateral damage of recurrent nerves, in 3 - transient hypoparathyroidism and in 1 - suppuration of the operating wound. As a rule, a multidisciplinary approach was used to treat complications. Histological examination of resected thyroid tissue was dominated by nodular colloid goiter in 79 patients $(71.5 \%)$, nodal toxic goiter was detected in 11 ones (9.7\%), autoimmune thyroiditis in $9(7.9 \%)$, adenomas in $5(4.4 \%)$, cancer in 8 persons (7\%). Long-term results of treatment were studied in $78(69.6 \%)$ patients in the period from 1 up to 5 years. In 17 patients $(21.7 \%)$ relapses of nodal formations were detected in the 1-st year after the operation, in 1-3 years in 15 patients (19.2\%), and in later terms in $11(14.1 \%)$ patients. Thus, in $32(41 \%)$ patients, the recurrence of the disease developed in the early period after surgical interventions. The most common cause of recurrence of goiter was the deficiencies committed during the operation (insufficient revision of the thyroid gland, abandonment of altered areas or small thyroid nodules, complication during surgery, which did not allow it to be completed radically). According to our data, the relapse of the disease developed more often after surgery for multinodular goiter and depended not on preoperative and intraoperative diagnosis of multinodular goiter forms, but on the volume of the operation. The majority of patients with relapse of nodular goiter (73\%) complained about the presence of nodal education on the neck;in one third there were noted difficulty of swallowing, shortness of breath, weakness, fatigue, drowsiness. All patients with recurrent goiter after the examination were repeatedly operated under general anesthesia. Operations with recurrent goiter are difficult. The amount of surgical intervention at recurrent goiter - removal of all available thyroid tissue.Hypoparathyroidism was detected in 1 of the patient (1.2\%), a retracted postoperative scar in 2 ones $(2.4 \%)$, hypothyroidism in $5(6.4 \%)$ patients. After surgical interventions for the thyroid gland pathology, all 